\title{
BMJ Open Value of light microscopy to diagnose urogenital gonorrhoea: a diagnostic test study in Indonesian clinic-based and outreach sexually transmitted infections services
}

\author{
I Putu Yuda Hananta, ${ }^{1,2}$ Alje P van Dam, ${ }^{2,3}$ Sylvia Maria Bruisten, ${ }^{2,4}$ \\ Maarten Franciscus Schim van der Loeff, ${ }^{2,5}$ Hardyanto Soebono, ${ }^{6}$ \\ Henry John Christiaan de Vries ${ }^{1,5,2}$
}

To cite: Hananta IPY, van Dam AP, Bruisten SM, et al. Value of light microscopy to diagnose urogenital gonorrhoea: a diagnostic test study in Indonesian clinic-based and outreach sexually transmitted infections services. BMJ Open 2017;7:e016202. doi:10.1136/ bmjopen-2017-016202

- Prepublication history and additional material for this paper are available online. To view these files please visit the journal online (http://dx.doi. org/10.1136/bmjopen-2017016202).

Received 31 January 2017 Revised 19 June 2017 Accepted 20 June 2017

\section{CrossMark}

For numbered affiliations see end of article.

Correspondence to Dr. Henry John Christiaan de Vries; h.j.devries@amc.nl

\section{ABSTRACT}

Introduction Gonorrhoea is a common sexually transmitted disease caused by Neisseria gonorrhoeae $(\mathrm{Ng})$ infection. Light microscopy of urogenital smears is used as a simple tool to diagnose urogenital gonorrhoea in many resource-limited settings. We aimed to evaluate the accuracy of light microscopy to diagnose urogenital gonorrhoea as compared with a PCR-based test.

Methods In 2014, we examined 632 male urethral and 360 endocervical smears in clinic-based and outreach settings in Jakarta, Yogyakarta and Denpasar, Indonesia. Using the detection of Ng DNA by a validated PCR as reference test, we evaluated the accuracy of two light microscopic criteria to diagnose urogenital gonorrhoea in genital smears: (1) the presence of intracellular Gramnegative diplococci (IGND) and (2) $\geq 5$ polymorphonuclear leucocytes (PMNL)/oil-immersion field (oif) in urethral or $\geq 20 \mathrm{PMNL} /$ oif in endocervical smears.

Results In male urethral smears, IGND testing had a sensitivity $(95 \% \mathrm{Cl})$, specificity $(95 \% \mathrm{Cl})$ and kappa \pm SE of $59.0 \%$ (50.1 to 67.4$), 89.4 \%$ (86.3 to 91.9 ) and $0.49 \pm 0.04$, respectively. For PMNL count, these were $59.0 \%$ (50.1 to 67.4 ), $83.7 \%$ (80.2 to 86.9 ) and $0.40 \pm 0.04$, respectively. The accuracy of IGND in the clinic-based settings ( $72.0 \%$ (57.5 to 83.3 ), $95.2 \%$ (91.8 to 97.5 ) and $0.68 \pm 0.06$, respectively) was better than in the outreach settings ( $51.2 \%$ ( 40.0 to 62.3 ), $83.4 \%$ (78.2 to 87.8 ) and $0.35 \pm 0.06$, respectively). In endocervical smears, light microscopy performed poorly regardless of the setting or symptomatology, with kappas ranging from -0.09 to 0.24 . Conclusion Light microscopy using IGND and PMNL criteria can be an option with moderate accuracy to diagnose urethral gonorrhoea among males in a clinic-based setting. The poor accuracy in detecting endocervical infections indicates an urgent need to implement advanced methods, such as PCR. Further investigations are needed to identify the poor diagnostic outcome in outreach services.

\section{INTRODUCTION}

Gonorrhoea, caused by Neisseria gonorrhoeae $(\mathrm{Ng})$, is the second most common bacterial
Strengths and limitations of this study

- This is the first study to evaluate light microscopy criteria to diagnose urogenital gonorrhoea in Indonesia.

- This is a multicentre study conducted in several participating clinics in three major cities in Indonesia.

- The technical fluency among clinicians and laboratory technicians working in clinic-based settings may differ from those working in outreach settings and influence the outcome, but this was not evaluated in our study.

- The clinical workload in the participating clinics was not prospectively measured but estimated in a post hoc analysis.

sexually transmitted infections (STIs) worldwide. ${ }^{1}$ The variety of diagnostic methods used in different settings and regions may influence the observed epidemiological patterns of gonorrhoea. ${ }^{12}$

Nowadays, nucleic acid amplification tests (NAATs) are considered the standard to diagnose gonorrhoea, both for male and female patients. ${ }^{3}$ However, NAAT is not always available due to high prices, the required infrastructure and the need for qualified personnel. ${ }^{4}$ As a result, a diagnostic method based on clinical symptoms and signs (syndromic approach) and/or light microscopic findings is currently the standard in many resource-limited countries, such as Indonesia. ${ }^{5}{ }^{6}$ Furthermore, resources are also scarce in an outreach setting, a form of service used frequently to reach target groups who are at risk of STI but have poorer access to institutionalised health centres, for example, sex workers, men who have sex with men (MSM) and transwomen. ${ }^{7}$ 
Syndromic approach is considered to be sensitive and specific in symptomatic males. ${ }^{568}$ Yet, this approach has been increasingly criticised because of its poor performance in diagnosing gonorrhoea among females and asymptomatic individuals. ${ }^{8-11}$ As a consequence, antibiotics are both overused and underutilised, and this fuels antimicrobial resistance and spread of infections because of underdiagnosis. ${ }^{8-10}$

Thus, in addition to syndromic approach, light microscopic examination of Gram-stained smears to support a urogenital gonorrhoea diagnosis is recommended. ${ }^{2} 612$ Two light microscopic findings are used as a criterion for urogenital gonorrhoea: an elevated number of polymorphonuclear leucocytes (PMNLs) and the presence of intracellular Gram-negative diplococci (IGND) ${ }^{2}{ }^{6}$

Since the widespread introduction of NAAT to screen for gonorrhoea is too costly and therefore not realistic in many resources-limited settings, we evaluated the performance of these two light microscopic criteria to diagnose urethral and endocervical gonorrhoea in clinic-based and outreach settings in three major cities in Indonesia: Jakarta, Yogyakarta and Denpasar, and compared them with detection of $\mathrm{Ng}$ with a PCR test (Ng-PCR) performed at the Public Health Laboratory of Amsterdam, the Netherlands.

\section{MATERIAL AND METHODS}

This study was approved by the Medical and Health Research Ethics Committee (MHREC), Faculty of Medicine Universitas Gadjah Mada (\#KE/FK/38/EC).

\section{Study population}

Between January and December 2014, two clinic-based and six outreach STI service facilities in Jakarta, Yogyakarta and Denpasar, Indonesia, recruited participants for the investigation of the epidemiology of urogenital gonorrhoea. ${ }^{13}$ The length of the recruitment period varied per clinic (from 1 month to 5 months). All accessible males, females and transwomen (who had not undergone genital reconstructive surgery) clients, who were aged 16 years or older at the day of inclusion and who provided written informed consent were consecutively screened regardless of other demographics and clinical characteristics.

The original aim of the study was to estimate prevalence of gonorrhoea among STI clinic clients in Indonesia and to assess the antibiotic susceptibility patterns of $N$. gonorrhoeae strains found in these clients. The current study is a post hoc, exploratory analysis, and no formal sample size calculation was performed.

\section{Data collection}

In the clinic-based setting, participants visited the clinics during regular service hours (daytime: 09:00-15:00; evening: 15:00-21:00), whereas in the outreach setting, healthcare providers visited the outreach venues, for example, community gatherings, saunas and massage parlours, not necessarily during regular service hours.
We used a paper-based self-administered questionnaire to assess participants' demographics, sexual history and clinical characteristics. In case of illiteracy or on request of the participant, a healthcare worker or counsellor assisted in completing the questionnaire. In the outreach setting, several participants might complete the questionnaire at the same moment.

Symptomatic participants were defined as those who reported the presence of genital discharge and/or pain at the day of consultation.

In both settings, samples were examined on site. A clinician collected one urogenital sample per participant (from the urethra of males and transwomen, or the endocervix of females) using an ESwab (Copan Italia S.P.A., Brescia, Italy) ${ }^{14}$ and produced the smear. A laboratory technician (with a minimum education in medical laboratory or biomedical science, and a training in performing light microscopy according to Indonesian national STI guideline ${ }^{6}{ }^{6}$ ) performed Gram staining and examined the samples by light microscopy. The first light microscopic criterion was the PMNLs count. The cut-off value for a positive result was prespecified according to the guideline as $\geq 5 \mathrm{PMNL} /$ oil-immersion field (oif) for urethral samples and $\geq 20 \mathrm{PMNL} /$ oif for endocervical samples. ${ }^{6}$ The second light microscopic criterion was the presence of IGND. ${ }^{6}$

From all participating clinics, collected urogenital samples were transferred in ESwab medium (Copan Italia S.P.A.) to the Research Laboratory Facility (Fasilitas Penelitian Bersama-FALITMA), Faculty of Biology Universitas Gadjah Mada in Yogyakarta, Indonesia, and stored at $-80^{\circ} \mathrm{C}$ before they were transferred on dry ice to the reference laboratory at Public Health Service (GGD) of Amsterdam, the Netherlands, for Ng-PCR. ${ }^{14}$ At the reference laboratory, DNA was extracted from the samples by isopropanol precipitation. Presence of $\mathrm{Ng}$ was tested by detecting opa genes in the validated Ng-PCR, as described. ${ }^{15}$ The procedure was performed in the Rotorgene system (Qiagen N.V, Venlo, the Netherlands) using protocol, primers and probes, as described. ${ }^{16}$ Sensitivity and specificity of the PCR method in an earlier study were $95 \%$ and $99 \%$, respectively. ${ }^{15}$ Performers of PCR were blinded for the results of light microscopy. The use of Indonesian national guideline for the management for STI for light microscopy ${ }^{6}$ and the protocol of the reference laboratory for the PCR ensured that all participants had complete and conclusive laboratory data for the analysis. A subset of samples that were IGND positive but were negative in Ng-PCR was sent to the Netherlands Reference Laboratory for Bacterial Meningitis, Amsterdam, for investigation of the presence of Neisseria meningitidis, as described. ${ }^{17}$

In addition, data on daily number of inclusions, number of samples examined and number and job description of staff involved in the study were collected from participating clinics as part of study administration. 


\section{Statistical analysis}

Statistical analysis was performed in STATA V.13. Demographics, sexual history and clinical characteristics of the participants were described, overall and by service setting.

Separate analyses of diagnostic accuracy were performed for urethral (from male and transwomen) and endocervical samples. Diagnostic accuracy of the two light microscopy criteria compared with the reference test, Ng-PCR, was assessed by calculating sensitivity, specificity, positive predictive value (PPV) and negative predictive value (NPV) and their 95\% CI using two-by-two contingency tables, and also by calculating Cohen's kappa coefficient and its SE. ${ }^{18}$ We performed exploratory analyses to examine the differences in sensitivity and specificity by microscopy criteria (using McNemar's test) and by service settings and symptomatology (using $\chi^{2}$ test).

We performed a post hoc analysis to describe participating clinic's performance. We described number and job description of staff involved in the study. Clinic's workload was described as the number of samples examined per hour based on daily number of inclusions, number of samples examined and time spent for sample analysis (estimated).

\section{RESULTS}

\section{Characteristics of participants and participating clinics}

In total, data of 992 participants were examined: 632 males (including 97 transwomen) (table 1, supplementary figures 1-3) and 360 females (table 2, online supplementary figures 4-6). Part of the study population and their characteristics were included in an earlier report. ${ }^{13}$ Of the males, $47.6 \%$ were recruited in clinic-based and $52.4 \%$ in outreach settings, $53.6 \%$ were MSM and $17.3 \%$ had symptoms. Of the females, $92.2 \%$ were recruited in outreach settings, $86.4 \%$ were sex workers and $28.1 \%$ had symptoms.

Among participants visiting clinic-based settings, the proportion of those who were symptomatic was higher (22.6\% and $60.7 \%$, respectively, for males and females) than among participants who were seen in the outreach settings (12.4\% and 25.3\%). Participants seen in the outreach setting were more often notified by a partner (37.5\% and $25.6 \%$, respectively, for males and females) than participants seen in the clinic-based settings (14.9\% and $3.6 \%)$. In addition, most of male $(55.9 \%)$ and female participants $(84.4 \%)$ in the outreach settings reported sexual activity in the 3 days preceding the day of consultation, while this was only $22.6 \%$ and $32.1 \%$ respectively of those visiting the clinic-based settings.

In the post hoc estimation, total sample analysis time spent in clinic-based and outreach settings during the study period was estimated to be 512 and 276 hours, respectively, and the workload was estimated to be 0.54 and 2.40 samples per hour, respectively (see table 3 ).
Diagnostic accuracy of light microscopy results compared with $\mathrm{Ng}$-PCR

The prevalence of urogenital gonorrhoea based on $\mathrm{Ng}$-PCR in this study population was $21.2 \%$ in males/ transwomen (table 4) and $28.9 \%$ in women (table 5 ). The prevalence in males/transwomen was $16.6 \%$ and $25.4 \%$, respectively, for the clinic-based setting and for the outreach setting $\left(\chi^{2}\right.$ test, $\left.\mathrm{p}<0.01\right)$. In women, this was $42.9 \%$ and $27.7 \%$ ( $\chi^{2}$ test, $\mathrm{p}=0.09$ ).

For urethral infections in males/transwomen, sensitivity $(95 \% \mathrm{CI})$, specificity $(95 \% \mathrm{CI})$ and kappa $\pm \mathrm{SE}$ of PMNL were $59.0 \%$ (50.1 to 67.4 ), $83.7 \%$ (80.2-86.9) and $0.40 \pm 0.04$ and of IGND were $59.0 \%$ (50.1 to 67.4 ), $89.4 \%$ (86.3 to 91.9 ) and $0.49 \pm 0.04$, respectively (table 4 ). IGND and PMNL differed significantly in specificity $\left(\chi^{2}\right.$ test, $\mathrm{p}<0.001)$. Using IGND as diagnostic criterion for urethral gonorrhoea, clinic-based settings performed better $(72.0 \%$ (57.5 to 83.8 ), $95.2 \%$ (91.8 to 97.5$)$ and $0.68 \pm 0.06)$ than outreach settings $(51.2 \%$ (40.0 to 62.3 ), $83.4 \%$ ( 78.2 to 87.8 ) and $0.35 \pm 0.06$ ).

We also observed a better performance in clinic-based settings compared with outreach settings when PMNL was used as the diagnostic criterion. Both IGND and PMNL gave better accuracy if compared with syndromic approach. Sensitivity, specificity and kappa \pm SE of syndromic approach for males/transwomen was $20.2 \%$ (13.7 to 28.0 ), 83.5\% (80.0 to 86.7) and $0.04 \pm 0.04$, respectively.

For endocervical infection in females, overall sensitivity, specificity and kappa \pm SE of PMNL were respectively $31.7 \%$ (23.0 to 41.6 ), $68.0 \%$ (61.9 to 73.6 ) and $0.00 \pm 0.05$, respectively; of IGND, these were $31.7 \%$ (23.0 to 41.6 ), $84.8 \%$ (79.8 to 88.9 ) and $0.18 \pm 0.05$, respectively (table 5 ). The difference in specificity between IGND and PMNL was significant $\left(X^{2}\right.$ test, $\left.\mathrm{p}<0.001\right)$. Performances of microscopy were not significantly different from syndromic approach.

For both urethral and endocervical samples, we observed that all samples that were positive for IGND were also positive for the PMNL criterion. In addition, out of 53 male urethral and 39 endocervical samples that were IGDN positive but Ng-PCR negative, none of the samples were positive for N. meningitidis DNA.

\section{DISCUSSION}

Our study showed that light microscopic examination of Gram-stained urethral smears has some added value to diagnose gonorrhoea in males/transwomen, compared with the syndromic management based on signs and symptoms only. Furthermore, the IGND criterion in male urethral samples showed a better accuracy than PMNL, that is, a similar sensitivity, but higher specificity, PPV, NPV and kappa coefficient. Yet, for endocervical samples, light microscopy criteria have no added value over syndromic approach, as both the IGND and PMNL criteria performed poorly. 
Table 1 Demographics and clinical characteristics of 632 male/transwoman participants recruited in Jakarta, Yogyakarta and Denpasar (January-December 2014)

\begin{tabular}{|c|c|c|c|c|}
\hline & All $(n=632)$ & Clinic based $(n=301)$ & Outreach $(n=331)$ & \\
\hline Variables & n (\%) & n (\%) & n (\%) & p Values \\
\hline City of recruitment & & & & $<0.001$ \\
\hline Jakarta & $153(24.2)$ & $0(0.0)$ & $153(46.2)$ & \\
\hline Yogyakarta & $221(35.0)$ & $43(14.3)$ & $178(53.8)$ & \\
\hline Denpasar & $258(40.8)$ & $258(85.7)$ & $0(0.0)$ & \\
\hline Median age $(\mathrm{IQR})^{*}$, in years & $27(24-33)$ & 27 (24-32) & $27(23-35)$ & 0.64 \\
\hline Age group & & & & $<0.001$ \\
\hline $16-24$ years & $201(31.8)$ & $82(27.2)$ & $119(35.9)$ & \\
\hline 25-34 years & $290(45.9)$ & $165(54.8)$ & $125(37.8)$ & \\
\hline$\geq 35$ years & $141(22.3)$ & $54(17.9)$ & $87(26.3)$ & \\
\hline Risk group & & & & $<0.001$ \\
\hline Male sex workers & $167(26.4)$ & $62(20.6)$ & $105(31.7)$ & \\
\hline Men who have sex with men & $339(53.6)$ & $210(69.8)$ & $129(39.0)$ & \\
\hline Transwomen* & $97(15.4)$ & $3(1.0)$ & $94(28.4)$ & \\
\hline Heterosexuals who are not sex workers & $29(4.6)$ & $26(8.6)$ & $3(0.9)$ & \\
\hline $\begin{array}{l}\text { Being notified of possibility contracting STI } \\
\text { from partner(s) } \dagger\end{array}$ & & & & $<0.001$ \\
\hline No & $463(73.3)$ & $256(85.1)$ & $207(62.5)$ & \\
\hline Yes & $169(26.7)$ & $45(14.9)$ & $124(37.5)$ & \\
\hline $\begin{array}{l}\text { Time between last sex contact and the day of } \\
\text { consultation }\end{array}$ & & & & $<0.001$ \\
\hline 0 days & $45(7.1)$ & $14(4.7)$ & $31(9.4)$ & \\
\hline 1-3 days & $208(32.9)$ & $54(17.9)$ & $154(46.5)$ & \\
\hline 4-7 days & $114(18.0)$ & $55(18.3)$ & $59(17.8)$ & \\
\hline$>7$ days & $265(41.9)$ & $178(59.1)$ & $87(26.3)$ & \\
\hline Urogenital symptoms $\ddagger$ & & & & 0.001 \\
\hline No & $523(82.8)$ & $233(77.4)$ & $290(87.6)$ & \\
\hline Yes & $109(17.3)$ & $68(22.6)$ & $41(12.4)$ & \\
\hline Reported history of STI§ & & & & 0.37 \\
\hline No & $414(65.5)$ & $192(63.8)$ & $222(67.1)$ & \\
\hline Yes & $136(21.5)$ & $72(23.9)$ & $64(19.3)$ & \\
\hline Unsure & $82(13.0)$ & $37(12.3)$ & $45(13.6)$ & \\
\hline Reported past antibiotics use§ & & & & 0.11 \\
\hline No & $423(66.9)$ & $200(66.5)$ & $223(67.4)$ & \\
\hline Yes & $139(22.0)$ & 60 (19.9) & 79 (23.9) & \\
\hline Unsure & $70(11.1)$ & $41(13.6)$ & $29(8.8)$ & \\
\hline
\end{tabular}

*Median value with IQR.

†In the preceding 3 months, including the day of consultation.

$\ddagger$ Reported genital discharge and/or genital pain at the day of consultation.

$\S$ In the preceding 3 months, not including the day of consultation.

Ip Values calculated using $\chi^{2}$ test for categorical variables or Kruskal-Wallis test for continuous variables.

STI, sexually transmitted infection.

Overall, the accuracy of light microscopy for male urethral and endocervical samples in our study was poorer than those reported by previous studies. $^{12} 1920$ This was possibly caused by different criteria used in defining the outcomes of microscopy and/or by different methods used as a reference test. We examined the accuracy of each criterion (PMNL and IGND) independently, while previous studies mostly combined these criteria to define the outcome of microscopy. 
Table 2 Demographics and clinical characteristics of 360 female participants recruited in Jakarta and Yogyakarta (JanuaryDecember 2014)

\begin{tabular}{|c|c|c|c|c|}
\hline & All $(n=360)$ & Clinic based $(n=28)$ & Outreach $(n=332)$ & \\
\hline Variables & n (\%) & n (\%) & n (\%) & p Values? \\
\hline City of recruitment & & & & $<0.001$ \\
\hline Jakarta & $232(64.4)$ & $0(0.0)$ & $232(69.9)$ & \\
\hline Yogyakarta & $128(35.6)$ & $28(100.0)$ & $100(30.1)$ & \\
\hline Median age $(\mathrm{IQR})^{\star}$, in years & $30(24-36.5)$ & $29(24-37.5)$ & $30(24-36)$ & 0.05 \\
\hline Age group & & & & 0.55 \\
\hline 16-24 years & $102(28.3)$ & $8(28.6)$ & $94(28.3)$ & \\
\hline 25-34 years & $146(40.6)$ & $9(32.1)$ & $137(41.3)$ & \\
\hline$\geq 35$ years & $112(31.1)$ & $11(39.3)$ & $101(30.4)$ & \\
\hline \multicolumn{5}{|l|}{ Risk group } \\
\hline Female sex workers & $311(86.4)$ & $3(10.7)$ & $308(92.8)$ & $<0.001$ \\
\hline Heterosexuals who are not sex workers & 49 (13.6) & 25 (89.3) & $24(7.2)$ & \\
\hline $\begin{array}{l}\text { Being notified of possibility contracting STI } \\
\text { from partner(s) } \dagger\end{array}$ & & & & 0.009 \\
\hline No & $274(76.1)$ & $27(96.4)$ & $247(74.4)$ & \\
\hline Yes & $86(23.9)$ & $1(3.6)$ & $85(25.6)$ & \\
\hline $\begin{array}{l}\text { Time between last sex contact and the day } \\
\text { of consultation }\end{array}$ & & & & $<0.001$ \\
\hline 0 days & 49 (13.6) & $0(0.0)$ & 49 (14.8) & \\
\hline $1-3$ days & $240(66.7)$ & $9(32.1)$ & $231(69.6)$ & \\
\hline 4-7 days & $38(10.6)$ & $11(39.3)$ & $27(8.1)$ & \\
\hline$>7$ days & $33(9.2)$ & $8(28.6)$ & $25(7.5)$ & \\
\hline Urogenital symptoms $\ddagger$ & & & & $<0.001$ \\
\hline No & 259 (71.9) & $11(39.3)$ & $258(74.7)$ & \\
\hline Yes & $101(28.1)$ & $17(60.7)$ & $84(25.3)$ & \\
\hline Reported history of STI§ & & & & 0.72 \\
\hline No & $297(82.5)$ & $24(85.7)$ & $273(82.2)$ & \\
\hline Yes & $42(11.7)$ & $2(7.1)$ & $40(12.1)$ & \\
\hline Unsure & $21(5.8)$ & $2(7.1)$ & $19(5.7)$ & \\
\hline Reported past antibiotics use§ & & & & 0.002 \\
\hline No & $146(40.6)$ & $20(71.4)$ & $126(37.9)$ & \\
\hline Yes & $171(47.5)$ & $6(21.4)$ & $165(49.7)$ & \\
\hline Unsure & $43(11.9)$ & $2(7.1)$ & 41 (12.4) & \\
\hline
\end{tabular}

${ }^{*}$ Median value with IQR.

†In the preceding 3 months, including the day of consultation.

†Reported genital discharge and/or genital pain at the day of consultation.

$\S$ In the preceding 3 months, not including the day of consultation.

Ip Values calculated using $\chi^{2}$ test for categorical variables or Kruskal-Wallis test for continuous variables.

STI, sexually transmitted infection.

The presence of diplococcus (IGND) could be a strong indication for $\mathrm{Ng}$ infection. ${ }^{2}$ However, a negative PCR result in an IGND-positive sample could result from misinterpretation in microscopy. ${ }^{3}$ Various morphotypes other than $\mathrm{Ng}$ could also be found in urogenital samples and may resemble IGND, for example, other members of the Neisseriaceae family and Moraxella catarrhalis. ${ }^{2122}$ N. meningitidis, for example, is commensal to human oro-pharynx but has also been described as a pathogen in urethritis in males. ${ }^{22}$ In this study, however, we could exclude urogenital tract colonisation by N. meningitidis as an explanation for the PCR-negative and IGND-positive cases.

In contrast, the presence of PMNL is an indication for inflammation that could be caused by a variety of microorganisms, including bacteria (eg, Chlamydia trachomatis and Mycoplasma genitalium), viruses and parasites and also 


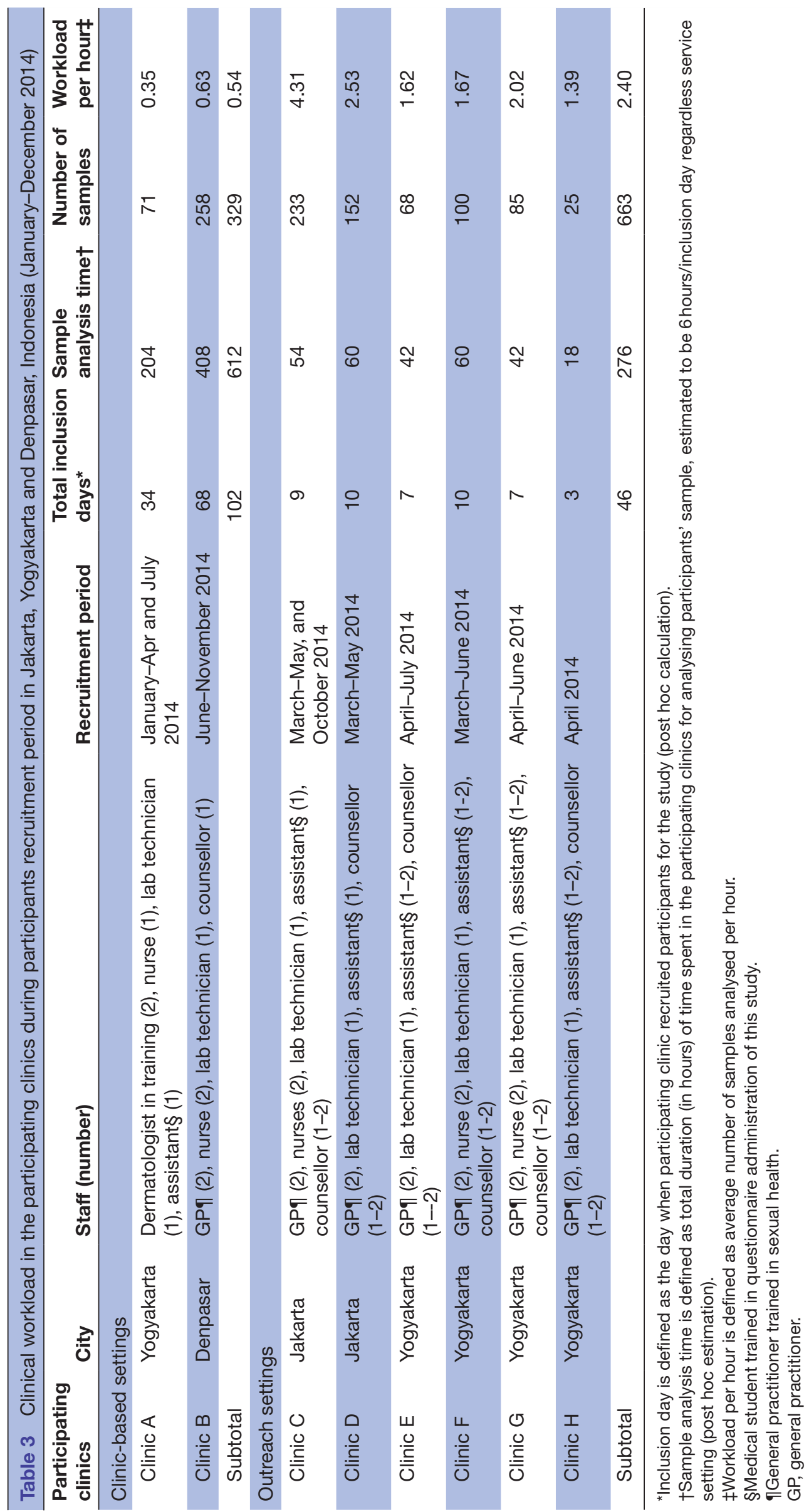




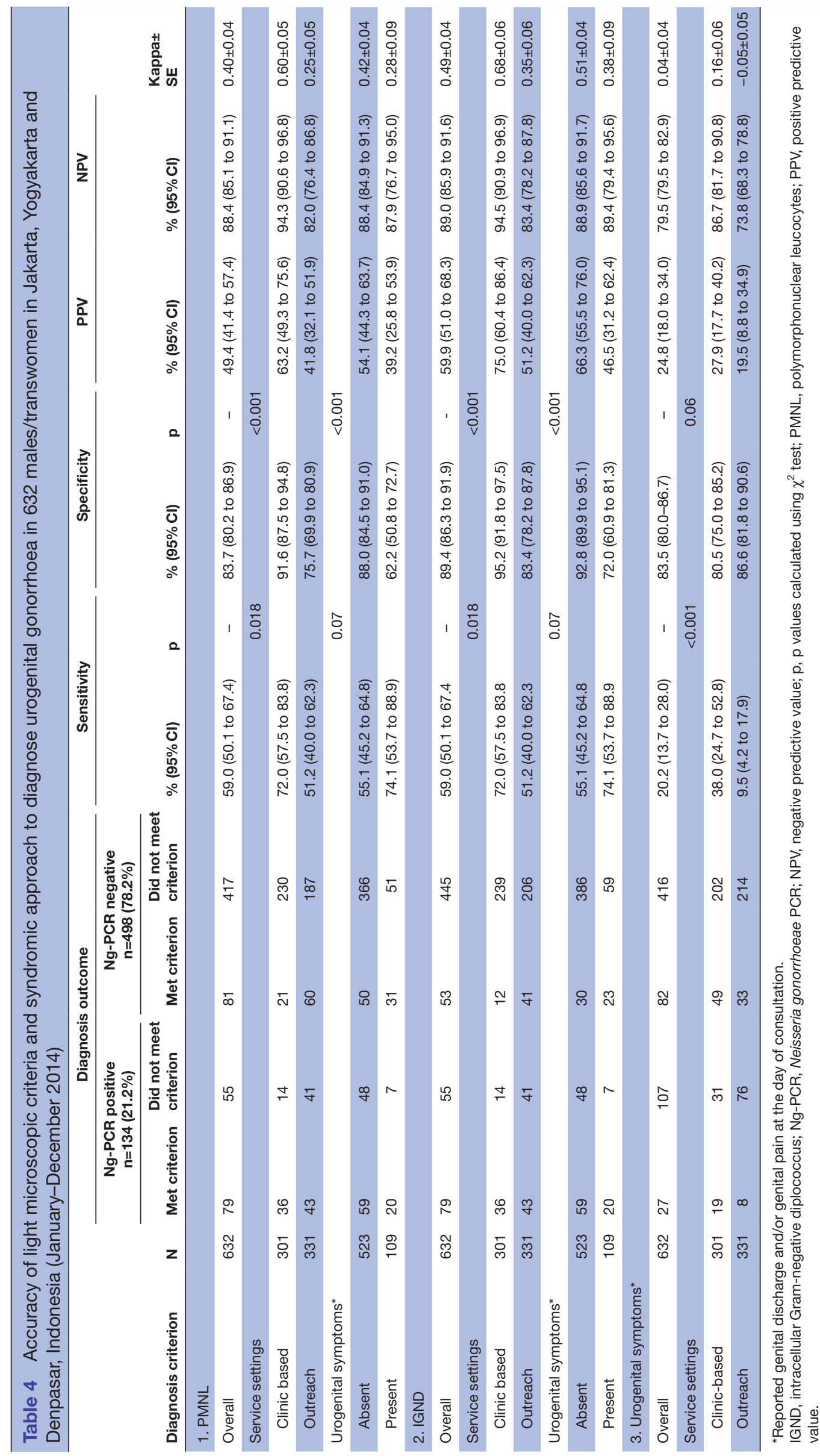




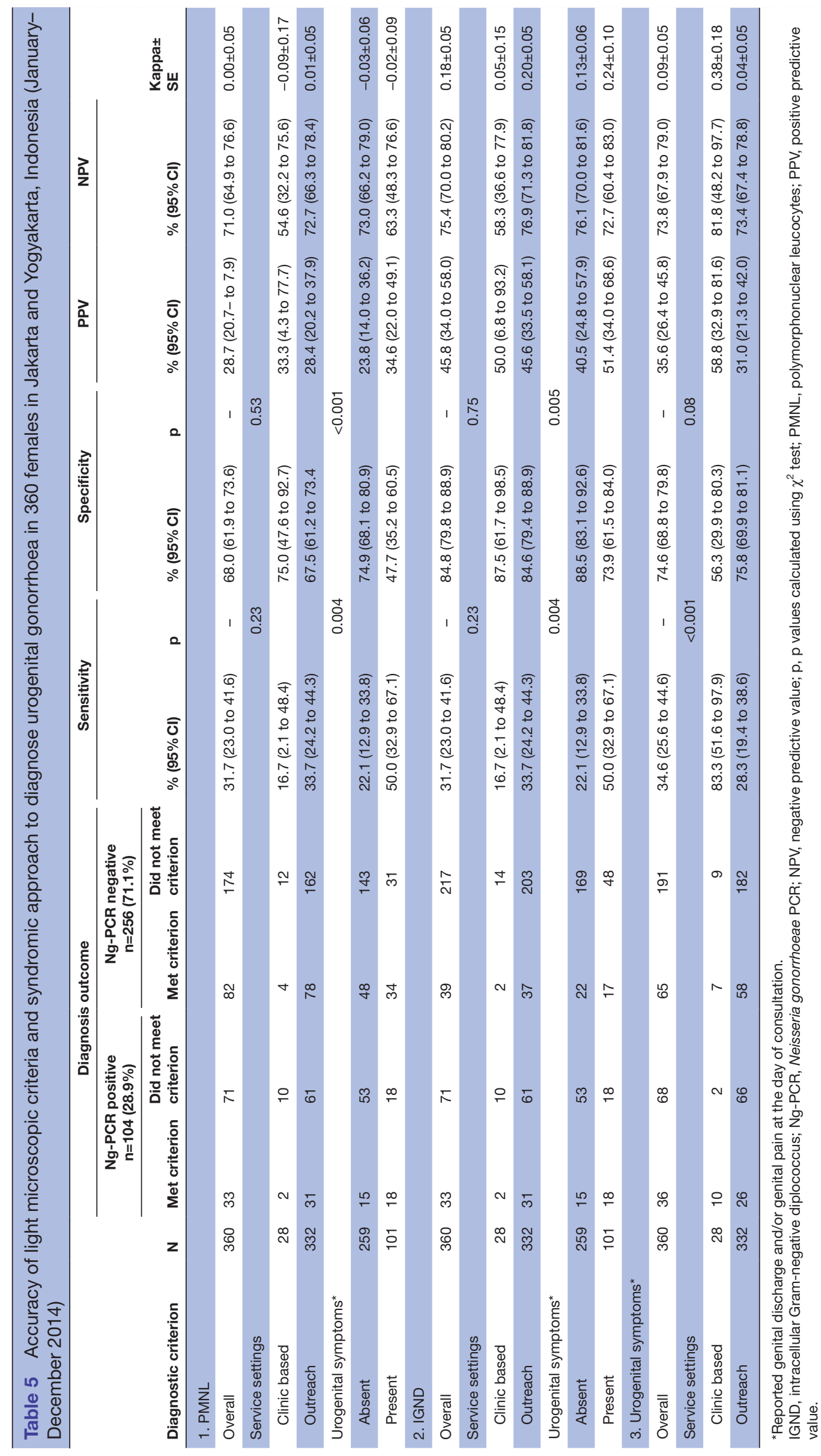


by mechanical damage. ${ }^{21-24}$ PMNLs are also observable in the female genital tract due to dysbiosis. ${ }^{20} 21$ Thus, PMNL count is not an accurate parameter concerning specific cause of inflammation. Furthermore, 5\% of urethral gonococcal infections diagnosed by NAAT showed no signs of inflammation ( $\geq 5$ PMNL cells/oif).$^{25}$

Since we observed that all IGND positive samples in our study were also positive for the PMNL criterion, it might be preferable to only use IGND as a diagnostic criterion for urogenital gonorrhoea and set aside the PMNL count. However, accuracy of both IGND and PMNL criteria may be reduced in case the male client has recently urinated. ${ }^{21}$

For diagnosing endocervical gonococcal infections, performing microscopy on endocervical samples has no additional value for the diagnosis of urogenital gonorrhoea since the sensitivity and the specificity of both microscopic criteria were poor, as described, ${ }^{3}$ and were similar to that of syndromic management. In cervical and vaginal smears, it is possible to miss IGND due to a low load $\mathrm{Ng}$ infection, an abundance of PMNL, debris or high loads of other bacteria that predominate over IGND. ${ }^{19} 20$

To analyse urogenital smears for the presence of IGND, the Gram-staining procedure is the preferable method advised. ${ }^{226}$ Other methods like methylene blue or crystal violet lack the required distinction of Gram-negative from Gram-positive diplococci and may be useful only for investigating urethral infection. ${ }^{26}$ This implies that the accuracy of light microscopy may be influenced by instrumental factors (such as the quality of the staining chemicals and the condition of the microscope), as well as technical fluency of staff members and their compliance to the procedural standard in obtaining the samples, preparing and staining the smears and examining slides by microscopy. ${ }^{225}$

In addition, we observed that the accuracy of light microscopic examination for urethral samples was moderate in the clinic-based settings but was much poorer in the outreach settings. Individuals recruited in outreach settings of our study, males and transwomen particularly, were at relatively higher risk than those recruited in clinic-based settings; this is reflected in a higher positivity rate of urethral infections. Disease prevalence may influence performance of a diagnostic test, including predictive values and kappa. ${ }^{18} 27$ For example, a population with a higher disease prevalence may include more severely diseased patients; therefore, the test performs better in this population. ${ }^{27}$

The variability of light microscopy accuracy may also be related to the clinical workload of the participating clinics. ${ }^{728}$ Clinic-based settings had a much lower workload per hour compared with outreach settings. The length of time allocated for sample analysis may influence the compliance of the clinicians and the laboratory technicians to the procedure and thus affect the accuracy of the test. When the allocated time is limited, specificity decreases. Proportion of clients to healthcare workers is an important variable that influences the clinical workload. ${ }^{728-30}$
Here we show that the number of female clients (who were mostly sex workers) visiting outreach settings is by far higher than those in clinic-based settings. Outreach settings play a significant role in STI service delivery in Indonesia as they are preferred by members of key populations (including female sex workers), yield a high rate of case detection and are potentially more cost-effective. ${ }^{71328-30}$ Therefore, improving the quality of STI service in the outreach settings, including achieving a more rational clinical workload and maintaining the technical fluency of staff members, seems to be important.

In this study we also confirm that the use of syndromic approach for both male and female participants is not suitable to correctly diagnose a urogenital $\mathrm{Ng}$ infection, as reported..$^{8-10}$ However, evaluating symptoms might still be useful, as the accuracy of light microscopy is better (higher sensitivity and specificity) among symptomatic individuals. The presence of symptoms (genital discharge or pain), especially in males, possibly represents an actual and more severe type of gonococcal infection, in which PMNL and IGND are more likely to present under light microscopy examination of the smear. $^{821}$

\section{Limitations and strengths of the study}

Our study has several limitations. We did not have any data regarding the numbers and characteristics of STI clients who were potentially eligible but refused to participate in the study. A good comparison of the accuracy of light microscopy in diagnosing endocervical infections between clinic-based and outreach setting was difficult because of the disproportion in the number of females recruited in the two settings. Most female participants, who were sex workers, were recruited in outreach settings. This was probably related to confidential, non-judgemental and free-of-charge STI services in the outreach settings, which were preferred by the members of key populations, including female sex workers. ${ }^{29}{ }^{30}$ Our study was conducted in a population with high gonorrhoea prevalence; this needs to be considered in generalising our findings to other settings. In addition, definition of accuracy level based on kappa is arbitrary and is subject to multiple interpretations. ${ }^{18}$

The technical fluency among clinicians and laboratory technicians working in clinic-based settings as opposed to outreach settings may differ and influence the outcome, ${ }^{7}$ but this was not evaluated in our study. Furthermore, the clinical workload was not prospectively measured but estimated in a post hoc analysis.

Our study has also several strengths. This is the first study to evaluate light microscopy criteria to diagnose urogenital gonorrhoea in Indonesia. The study was performed in several participating clinics in three major cities in the country. In addition, to our knowledge, our observation regarding variability of the diagnostic accuracy by service setting has not been reported in earlier studies. 


\section{CONCLUSIONS}

A moderate accuracy of IGND as a light microscopic criterion implies that it can be used as an option for diagnosing urethral gonorrhoea in males/transwomen in low resource settings. Based on its poor performance, using light microscopy for diagnosing endocervical infection should be discouraged. More advanced methods, such as NAAT, should be considered if financial resources are available, especially for endocervical infections, and to screen asymptomatic individuals.

Further studies are needed to determine whether the poor performance in the outreach settings was associated with clinical workload, instrumental and technical problems and/or environmental factors.

\section{Author affiliations}

${ }^{1}$ Deartment of Dermatology, Academic Medical Center, University of Amsterdam, Amsterdam, Noord Holland, The Netherlands

${ }^{2}$ Department of Infectious Diseases, Public Health Service (GGD) of Amsterdam, Amsterdam, Noord Holland, The Netherlands

${ }^{3}$ Onze Lieve Vrouwe Gasthuis (OLVG) Hospital, Amsterdam, The Netherlands

${ }^{4}$ Center for Infections and Immunology Amsterdam (CINIMA), Academic Medical Center, University of Amsterdam, Amsterdam, The Netherlands

${ }^{5}$ Amsterdam Infection and Immunity Institute (AI\&II), Academic Medical Center, University of Amsterdam, Amsterdam, The Netherlands

${ }^{6}$ Department of Dermatology and Venereology, Faculty of Medicine, Universitas Gadjah Mada, Yogyakarta, Indonesia

Acknowledgements We would like to express our greatest appreciation to men, women and transwomen participating in this study. We would also like to thank the healthcare workers in the participating clinics: Dr. Sardjito General Hospital (Yogyakarta), Perkumpulan Keluarga Berencana Indonesia/Indonesian Planned Parenthood Association (Yogyakarta), Gedong Tengen Primary Health Care (Yogyakarta), Umbulharjo Primary Health Care (Yogyakarta), Yayasan Vesta (Yogyakarta), Yayasan People Like Us-Satu Hati (Yogyakarta), Keluarga Besar Waria Yogyakarta, Ikatan Waria Yogyakarta, Mangga Besar Primary Health Care (Jakarta), Yayasan Kusuma Buana (Jakarta), Yayasan Intermedika (Jakarta), Bali Medika Clinic (Denpasar), students and The Neisseria Project research assistants who contributed in data collection phase, laboratory technicians and management of Public Health Service (GGD) Amsterdam, Arie van der Ende, PhD, and the Netherlands Reference Laboratory for Bacterial Meningitis, and Indonesian Government, through Ministry of Research, Technology and Higher Education and Ministry of Health, for a good cooperation in supporting this research project.

Contributors IPYH, APvD, SMB, MSvdL, HS and HJdV contributed to the design of the study. IPYH performed data collection, cleaning and analyses. All authors contributed to the interpretation of data. IPYH prepared the manuscript draft, and all authors contributed in revising the manuscript critically for important intellectual content. HJdV contributed in giving final approval of the version to be published. All authors agreed to be accountable for all aspects of the work.

Funding This study was fully funded by the Ministry of Research, Technology, and Higher Education, Republic of Indonesia through the Excellence Scholarship (Beasiswa Unggulan) Program.

Competing interests None declared.

Patient consent Detail has been removed from this case description/these case descriptions to ensure anonymity. The editors and reviewers have seen the detailed information available and are satisfied that the information backs up the case the authors are making.

Ethics approval Institutional Research Board Faculty of Medicine Universitas Gadjah Mada Yogyakarta Indonesia.

Provenance and peer review Not commissioned; externally peer reviewed.

Data sharing statement № additional data are available.

Open Access This is an Open Access article distributed in accordance with the Creative Commons Attribution Non Commercial (CC BY-NC 4.0) license, which permits others to distribute, remix, adapt, build upon this work non-commercially, and license their derivative works on different terms, provided the original work is properly cited and the use is non-commercial. See: http://creativecommons.org/ licenses/by-nc/4.0/

(c) Article author(s) (or their employer(s) unless otherwise stated in the text of the article) 2017. All rights reserved. No commercial use is permitted unless otherwise expressly granted.

\section{REFERENCES}

1. Newman L, Rowley J, Vander Hoorn S, et al. Global estimates of the prevalence and incidence of four curable sexually transmitted infections in 2012 based on systematic review and global Reporting. PLoS One 2015;10:e0143304.

2. Unemo M, Ballard R, Ison $\mathrm{C}$, et al. Laboratory diagnosis of sexually transmitted infections, including human immunodeficiency virus. Geneve: WHO Press, 2013. http://www.who.int/reproductivehealth/ publications/rtis/9789241505840/en/. (accessed 20 Sep 2016).

3. Workowski KA, Bolan GA; Centers for Disease Control and Prevention. Sexually transmitted diseases treatment guidelines, 2015. MMWR Recomm Rep 2015;64:51-82.

4. Whiley DM, Tapsall JW, Sloots TP. Nucleic acid amplification testing for Neisseria gonorrhoeae: an ongoing challenge. J Mol Diagn 2006;8:3-15.

5. World Health Organization. Training modules for the syndromic management of sexually transmitted infections. 2nd ed. Geneve: WHO Press, 2007. http://www.who.int/reproductivehealth/ publications/rtis/9789241593407index/en/ (accessed 20 Mar 2016).

6. Ministry of Health Republic of Indonesia - Directorate General of Disease Control and Environmental Health. National guideline in the management of sexually transmitted infections. Bahasa Indonesia: Jakarta: Kemenkes RI, 2011.

7. Hengel B, Jamil MS, Mein JK, et al. Outreach for Chlamydia and gonorrhoea screening: a systematic review of strategies and outcomes. BMC Public Health 2013;13:1040-8.

8. Ghebremichael $M$. The syndromic versus laboratory diagnosis of sexually transmitted infections in Resource-Limited Settings. Isrn Aids 2014;2014:1-5.

9. Francis SC, Ao TT, Vanobberghen FM, et al. Epidemiology of curable sexually transmitted infections among women at increased risk for HIV in northwestern Tanzania: inadequacy of syndromic management. PLoS One 2014;9:e101221.

10. Otieno FO, Ndivo R, Oswago S, et al. Evaluation of syndromic management of sexually transmitted infections within the Kisumu Incidence Cohort Study. Int J STD AIDS 2014;25:851-9.

11. Mamahit ER, Rahardjo E, Lutam B, et al; Validation of the syndromic approach for the management of sexually transmitted infections in women with high risk behavior. . Bahasa Indonesia: Bul. Penelit. Kesehat, 2000:28. 460-72.

12. Bartelsman M, Straetemans M, Vaughan K, et al. Comparison of two gram stain point-of-care systems for urogenital gonorrhoea among high-risk patients: diagnostic accuracy and cost-effectiveness before and after changing the screening algorithm at an STI clinic in Amsterdam. Sex Transm Infect 2014;90:358-62.

13. Hananta IP, van Dam AP, Bruisten SM, et al. Gonorrhea in Indonesia: high prevalence of asymptomatic urogenital gonorrhea but no circulating extended spectrum Cephalosporins-Resistant Neisseria gonorrhoeae strains in Jakarta, Yogyakarta, and Denpasar, Indonesia. Sex Transm Dis 2016;43:608-16.

14. Wind CM, de Vries HJ, Schim van der Loeff MF, et al. Successful combination of nucleic acid amplification test Diagnostics and targeted deferred Neisseria gonorrhoeae culture. J Clin Microbiol 2015;53:1884-90.

15. Geraats-Peters CW, Brouwers M, Schneeberger PM, et al. Specific and sensitive detection of Neisseria gonorrhoeae in clinical specimens by real-time PCR. J Clin Microbiol 2005;43:5653-9.

16. Heymans R, Schouls LM, van der Heide HG, et al. Multiple-locus variable-number tandem repeat analysis of Neisseria gonorrhoeae. $J$ Clin Microbiol 2011;49:354-63.

17. Brouwer MC, Tunkel AR, van de Beek D. Epidemiology, diagnosis, and antimicrobial treatment of acute bacterial meningitis. Clin Microbiol Rev 2010;23:467-92.

18. Sim J, Wright CC. The kappa statistic in reliability studies: use, interpretation, and sample size requirements. Phys Ther 2005;85:257-68.

19. Shipitsyna E, Guschin A, Maximova A, et al. Comparison of microscopy, culture and in-house PCR and NASBA assays for diagnosis of Neisseria gonorrhoeae in Russia. APMIS 2008;116:133-8. 
20. Thorley N, Radcliffe K. The performance and clinical utility of cervical microscopy for the diagnosis of gonorrhoea in women in the era of the NAAT. Int J STD AIDS 2015;26:656-60.

21. Augenbraun $\mathrm{MH}, \mathrm{McC}$ cormak WM. Diseases of the reproductive organs and sexually transmitted diseases. In: Mandell GL, Bennett JE, Mandell DR, eds. Mandell, Douglas, and Bennett's principles and practice of infectious diseases. 7th ed.. Philadelphia: Churchil Livingstone Elsevier, 2014:1475-521.

22. Ito S, Hanaoka N, Shimuta K, et al. Male non-gonococcal urethritis: from microbiological etiologies to demographic and clinical features. Int J Urol 2016;23:325-31.

23. Sintsova A, Sarantis H, Islam EA, et al. Global analysis of neutrophil responses to Neisseria gonorrhoeae reveals a self-propagating inflammatory program. PLoS Pathog 2014;10:e1004341.

24. Edwards JL, Apicella MA. The molecular mechanisms used by Neisseria gonorrhoeae to initiate infection differ between men and women. Clin Microbiol Rev 2004;17:965-81.

25. Geisler WM, Yu S, Hook EW. Chlamydial and gonococcal infection in men without polymorphonuclear leukocytes on gram stain: implications for diagnostic approach and management. Sex Transm Dis 2005;32:630-4.

26. Taylor SN, DiCarlo RP, Martin DH. Comparison of methylene blue/ gentian violet stain to Gram's stain for the rapid diagnosis of gonococcal urethritis in men. Sex Transm Dis 2011;38:995-6.

27. Leeflang MM, Bossuyt PM, Irwig L. Diagnostic test accuracy may vary with prevalence: implications for evidence-based diagnosis. $J$ Clin Epidemiol 2009;62:5-12.

28. World Health Organization. Regional strategy for the prevention and control of sexually transmitted infections 2007-2015. New Delhi: WHO-SEARO Publishing and Sales, 2007. http://apps.searo.who.int/ pds_docs/B0563.pdf (accessed 20 Mar 2016).

29. Hayter M. Reaching marginalized young people through sexual health nursing outreach clinics: evaluating service use and the views of service users. Public Health Nurs 2005;22:339-46.

30. You JH, Wong WC, Sin CW, et al. The cost-effectiveness of an outreach clinical model in the management and prevention of gonorrhea and Chlamydia among Chinese female sex workers in Hong Kong. Sex Transm Dis 2006;33:220-7. 